\title{
Distribution of Nutrients in Sagami Bay during 1971-1973
}

\author{
Akiyoshi Kamatani, ${ }^{* 1}$ Norio Ogura, ${ }^{* 2}$ Nobutada Nakamoto, ${ }^{* 8}$ \\ Masaki FunakoshI, ${ }^{* 8}$ and Shizuo IWaTA** \\ (Received May 26, 1981)
}

\begin{abstract}
In the surface layer of Sagami Bay, the concentrations of phosphate, total inorganic nitrogen, and silicate showed seasonal fluctuations in the range of $0.02-0.7 \mu \mathrm{g}$ at. $\mathrm{P} l^{-1}$, less than $1.0-11 \mu \mathrm{g}$ at. $\mathrm{N} l^{-1}$, and less than 5-25 $\mu \mathrm{g}$ at. $\mathrm{Si} l^{-1}$. The following relation has been found for these elements:

$$
\mathrm{P}: \mathrm{N}: \mathrm{Si}=1: 12.7: 19.7
$$

The infusion of cold water into the subsurface layer was one of the important sources supplying considerable amounts of inorganic nutrients to the euphotic zone, particularly in summer. The amount of chlorophyll $a$ varied widely throughout the year, and no consistent relationship between the seasonal changes of chl. $a$ and the nutrients was observed.
\end{abstract}

This paper is a part of a study of distribution of inorganic nutrients over three years in Sagami Bay, which has been carried out under a project of IBP/PM section. Primary emphasis here is placed on the characteristics of the distribution of nutrients and their fluctuations.

Nitrate, ammonia, phosphate, chlorophyll $a$ and dissolved organic carbon were determined in samples collected from surface to $200 \mathrm{~m}$ depth at monthly intervals. The seasonal fuctuation of dissolved organic carbon has already been reported as a part of this work. ${ }^{1)}$

The fluctuation in nutrient levels in this bay was regulated by a combination of factors including regional hydrography, biological activity and meteorological events. An attempt was made to correlate such fluctuations with salinity and temperature as hydrographical indicators, and with chlorophyll a as an indicator of biological activity.

No comprehensive survey of nutrients has previously been made in this bay, and it is hoped that these results would be of value for future studies.

\section{Samples and Methods}

Water samples were collected monthly at fixed station in Sagami Bay $\left(34^{\circ} 55^{\prime} \mathrm{N}, 138^{\circ} 22^{\prime} \mathrm{E}\right)$ during the period from January 1971 to December 1973 onboard the $R / V$ Ushio-maru which belongs to Kanagawa Pref. Fisheries Experimental Station. The samples were collected with Nansen bottle at the depths of $0,10,20,30,50,75,100,150$, and $200 \mathrm{~m}$. Immediately after sampling they were stored in a deep freezer in polyethylene bottles. At the laboratory on land, samples were thawed at room temperature and filtered with precombusted Whatman GF/C glass fibre filters prior to analysis. Chl. $a$ on the filter was determined by the method of StrICKLAND and PARSON, ${ }^{22}$ and pheopigments by the method of LORENZEN. ${ }^{\text {s) }}$ Nutrients in the filtrate were analyzed by using the methods described in the Manual of Oceanographyic Observation in Japan.4)

\section{Results and Discussion}

\section{General Physical Properties}

The seasonal fluctuation of water temperature shown in Fig. 1 exhibits the well-known pattern. From January through April, the temperature varies between 14 and $16^{\circ} \mathrm{C}$ and this layer extends from the surface to depths of $100 \mathrm{~m}$ or more. The thermal stratification in surface water starts in May and is well developed from June to September, when the temperature of surface water increases to about $26^{\circ} \mathrm{C}$. Decreasing of temperature in

*1 Tokyo University of Fisheries, Konan-4, Minato, Tokyo 108, Japan (豏谷明盖: 東京水座大学).

*2 Faculty of Agriculture, Tokyo University of Agriculture and Technology, Fuchu, Tokyo 183, Japan (小 會紀雄: 東京輩工大学).

*a Faculty of Science, Shinshu University, Matsumoto, Nagano 390, Japan (中本浐忠 - 船越真樹：霝州大学).

* Kanagawa Pref. Fisheries Experimental Station, Misaki, Miura, Kanagawa 238-02, Japan (岩田静太：神 察川水試). 


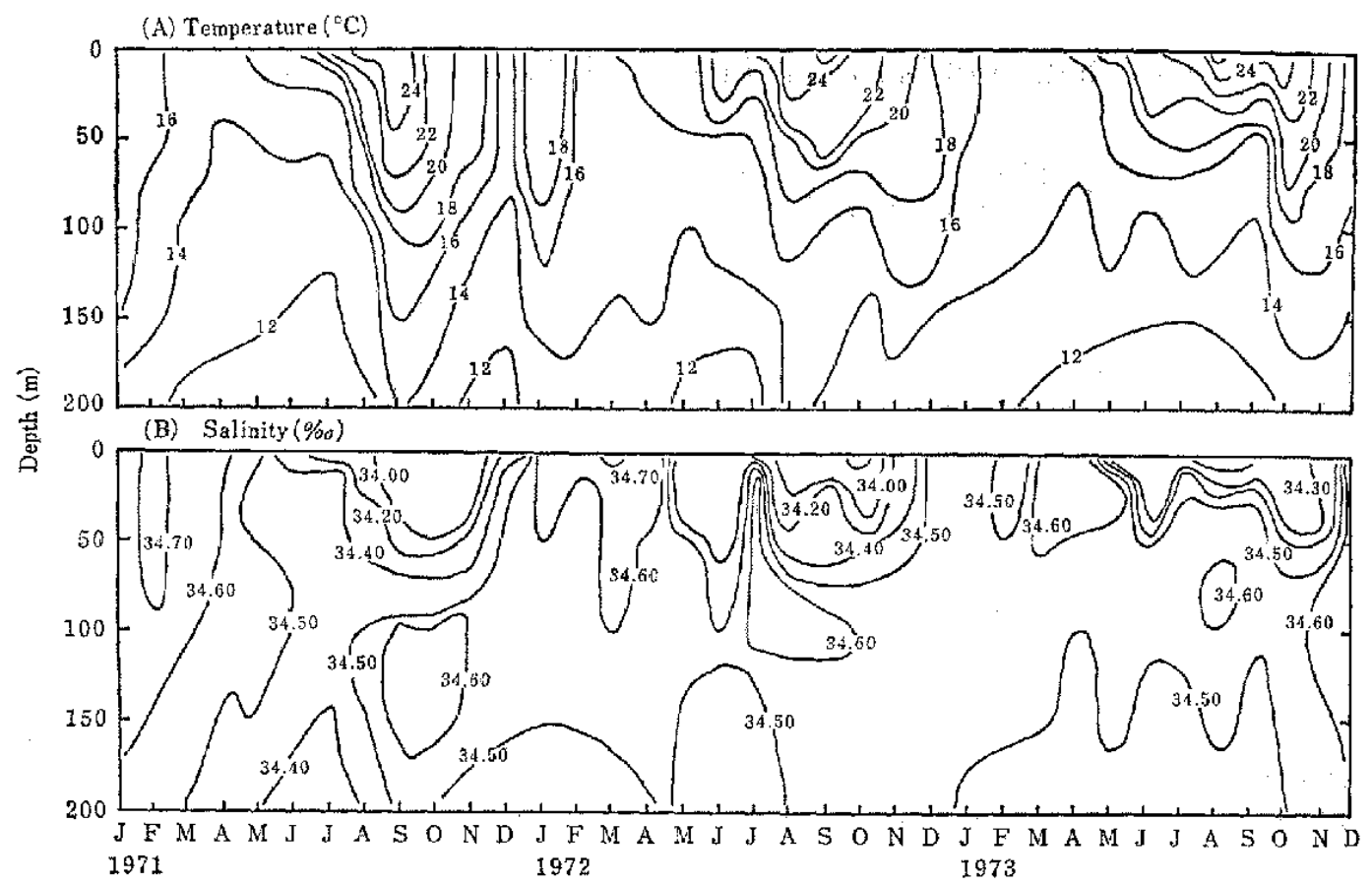

Fig. 1. Variations in the vertical distributions of temperature and salinity during 1971 through 1973.

surface water starts from the middle of Octorber and finally the seasonal thermocline disappeared during winter season.

The water temperature at $200 \mathrm{~m}$ depth shows a smaller seasonal fuctuation than the surface water, and also the fluctuating pattern is by no means similar: the maximum temperature in the surface water is usually observed during summer and the minimum temperature in winter, while at $200 \mathrm{~m}$ depth the water showing low temperature appeared in the months of June 1971, May 1972 and July 1973 , and warm waters even in the winter months of 1971 and 1972 (see Fig. 3), On referring to the data describing the Kuroshio path around this region (KAYYo SoKUHo), ${ }^{8}$ ) the fluctuation of temperature at $200 \mathrm{~m}$ was considered to closely as" sociate with the meandering of the Kuroshio axis; during the period that the Kuroshio or a branch of this current comes to onshore, the temperature at the deep water shows an increasing inclination and by offshoring the temperature drops as would be expected.

From the late spring to the autumn months, a layer of slightly lower salinity water $(32.0-34.0 \%$ ) is located on the seasonal thermocline, while during winter water with higher salinity $(34.50-34.60 \%$ ) extends from the surface to $100 \mathrm{~m}$ depth or more.
The salinity at $200 \mathrm{~m}$ depth shows small fluctuations throughout the year, ranging from 34.40 to 34.50\% (Fig. 1). The appearance of the lower salinity at this depth is consistent corresponds with its lower temperature.

\section{Distribution of Nutrients}

A significant fact brought out by the present investigation is that during summer the seasonal thermocline presents an effective barrier to the exchange of nutrients above and below it, and that during winter season, when a relatively constant temperature extends from the surface to $100 \mathrm{~m}$ depth or more by means of vertical mixing, the distribution of nutrients is also fairly homogeneous to the depth of $100 \mathrm{~m}$ or more (Figs. 1 and 2). Fig. 3 shows a rather interesting observation that the fiuctuation of phosphate at a depth larger than $75 \mathrm{~m}$ is strongly temperature dependent: the appearance of high phosphate concentration corresponds significantly with the infusion of cold water into subsurface layer, while the lower concentration is observed with a warm water infusion. To materialize this phenomenon, the plots of phosphate (silicate) against temperature at $200 \mathrm{~m}$ depth are illustrated in Fig. 4, suggesting that the concentration of phosphate increases at $0.18 \mu \mathrm{g}$ at. 


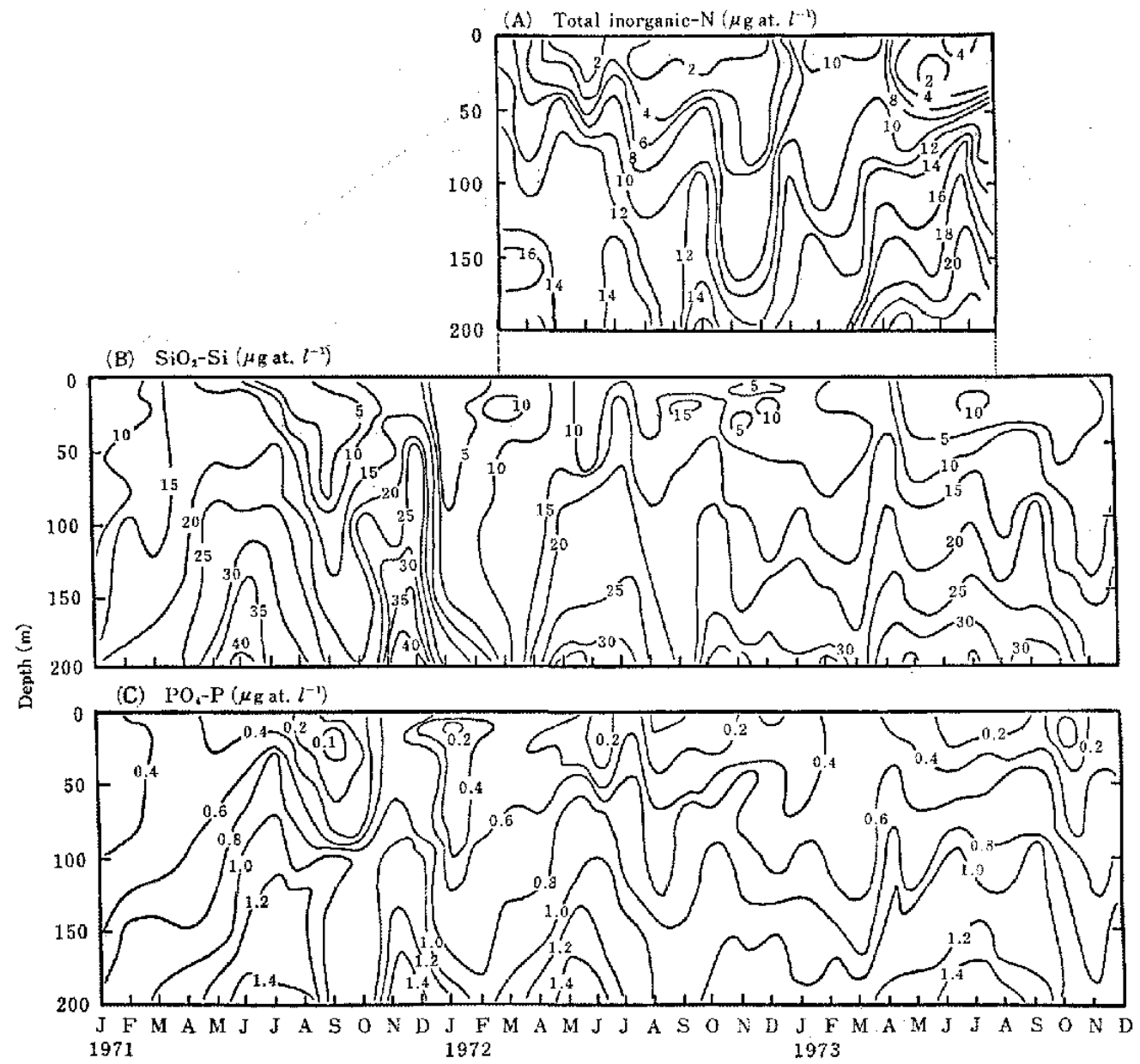

Fig. 2. Variations in the vertical distributions of total inorganic nitrogen, silicate, and phosphate during 1971 through 1973.

$l^{-1}$ with $1^{\circ} \mathrm{C}$ decreases in temperature and that the silicate at $5.5 \mu \mathrm{g}$ at. $l^{-1}$. The infusion of cold water into subsurface layer shows to supply an appropriate amounts of inorganic nutrients to the euphotic zone to support phytoplankton growth and productivity. The event is thought to be one of the important factors for maintaining the high productivity in Sagami Bay, particularly in summer when the developed seasonal thermocline suppresses the vertical mixing. It is strongly supported by the fact that the high concentration of chl. $a$ in July and August 1971 and May 1972 is linked together by the presence of the cold water (refer Figs. 3 and 8)

The phosphate concentration in surface water $(0-30 \mathrm{~m})$ shows a seasonal fiuctuation with the levels ranging from 0.02 to $0.8 \mu \mathrm{g}$ at. $l^{-1}$, and from
January to March with the homogeneous distribution extending from surface to the depth of $100 \mathrm{~m}$ or more (Fig. 2). The low values (0.1$0.3 \mu \mathrm{g}$ at. $l^{-1}$ ) usually occur in January in addition to the period from May to Octorber, except the unusual months in June and July 1971 and July 1972 when high values were observed (Fig. 5). The phosphate concentration in surface water decreased with developing of a seasonal thermocline, but the patterns changed irregularly from year to year. This irregularity must be caused by biological or physical actions or both. The typical exsamples are as follows.

Dispite the presence of cold water in subsurface layer as shown in Fig. 3, the surface waters in May and August 1971 and from May to July 1972 maintained the low concentration of phosphate. 


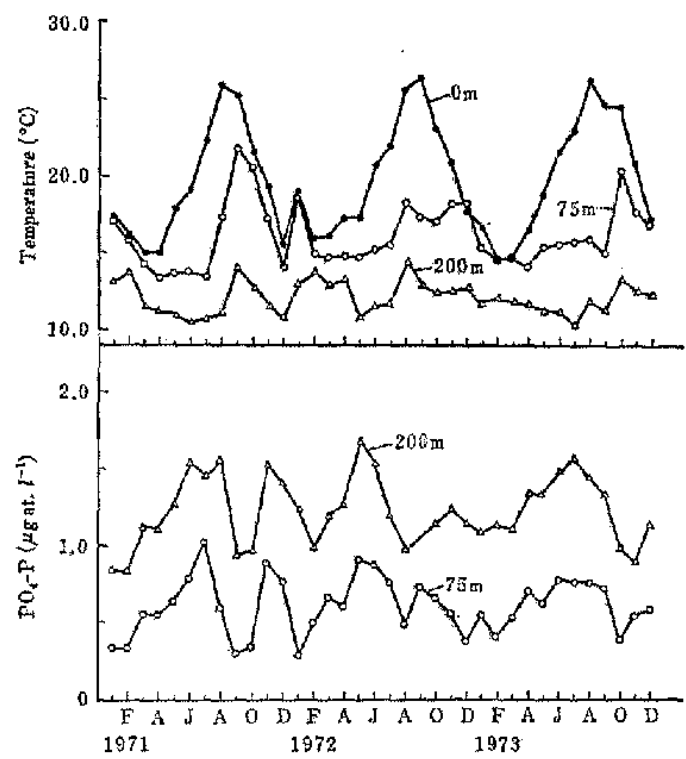

Fig. 3. Seasonal fiuctuations of phosphate and temperature at definit depths.

It is mostly expected to the phytoplankton bloom considering the high amount of pigments at these periods (Fig. 8). The low concentration of phosphate in August 1972 and Octorber 1973 could mostly be ascribed to the infusion of warm water into subsurface layer. On the other hand, the high value of phosphate in concurence with the maximum concentration of the pigments in July 1971 (Fig. 8) is difficult to explain clearly from the present data.

The silicate concentration in surface layer shows a seasonal fluctuation between 2 and $18 \mu \mathrm{g}$ at. $l^{-1}$ (Fig. 5). In 1971 the silicate concentration gradually increases from January to the maximum level of $18 \mathrm{~kg}$ at. $l^{-1}$ in April and then decreases to the minimum level of $4 \mu \mathrm{g}$ at. $l^{-1}$ in August. After September the concentration again increases up to $16 \mu \mathrm{g}$ at. $l^{-1}$ in December. From March through August in 1971, a cold water occupies the subsurface layer, but the drastic decline of silicate in surface water is observed from July to August. This period corresponded closely with the maximum amount of the pigments (refer Figs. 3 and 8). It, therefore, can be understood by the phenomenon that the ambient silicate was consumed by the temporal phytoplankton blooming quickly than silicate was supplied from subsurface layer into surface layer by the infusion of cold water. In 1972 the silicate concentrations exhibit unusual fluctuations throughout the year, retain-
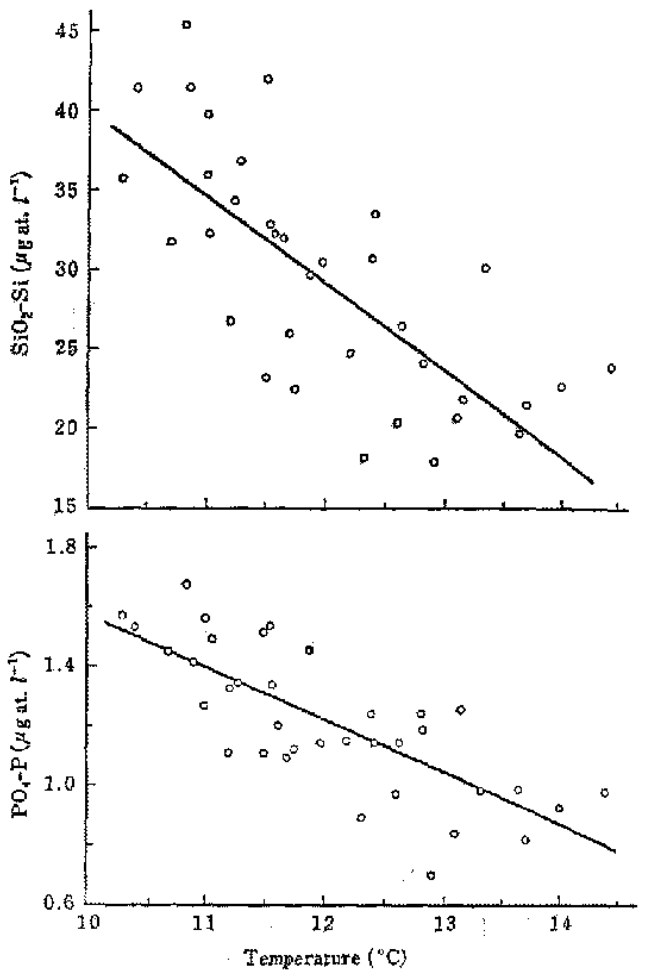

Fig. 4. Concentrations of phosphate and siticate corresponding to the temperature at $200 \mathrm{~m}$.

The relations between phosphate ( $\mathrm{P} \mu \mathrm{g}$ at. $l^{-1}$ ) and temperature $\left(\mathrm{t}^{\circ} \mathrm{C}\right)$ were approximated as $P=3.34-0.18 \mathrm{t} \quad(\mathrm{r}=-0.77)$, and the relations between silicate (Si $\mu \mathrm{g}$ at. $l^{-1}$ ) and temperature $\left(\mathrm{t}^{\circ} \mathrm{C}\right)$ were approximated as $\mathrm{Si}=94.5-5.5 \mathrm{t}(\mathrm{r}=$ -0.72 ).

ing relatively high value ranging from 6 to $12 \mu \mathrm{g}$ at. $I^{-1}$ in summer. Comparing with the previous two years, the water which shows the low silicate level ranging from 2 to $4 \mu \mathrm{g}$ at. $l^{-1}$, occupies the surface layer from the late spring through late autumn of 1973 , except July. The fiuctuation of silicate in surface water during summer was more dramatic event than other inorganic nutrients because the patches of high silicate concentration is offen caused by the surface run-off of coastal water having low salinity and high silicate.

In surface layer, the concentration of total inorganic nitrogen (sum of $\mathrm{NO}_{3}{ }^{-}, \mathrm{NO}_{2}{ }^{-}$, and $\mathrm{NH}_{4}{ }^{+}-\mathrm{N}$ ) varies between 1.0 and $10 \mu \mathrm{g}$ at. $l^{-1}$. From a qualitative point of view, the seasonal fluctuations of the nitrogen are essentially similar to those of phosphate: during summer when the seasonal ther* mocline effectively prevents the replenishment of nutrients from deep water, the level of the nitrogen 

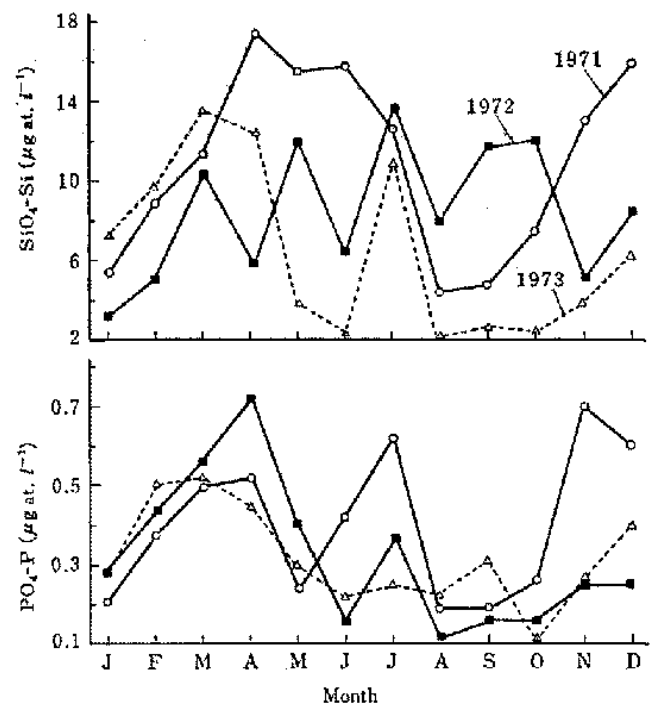

Fig. 5. Seasonal fluctuations of phosphate and silicate in surface water.

decreased to about $1.0 \mu \mathrm{g}$ at. $l^{-1}$. During this period, ammonia was in general the predominant component at the nitrogen in the surface water.

\section{Nutrient Relationship}

Figure 6 shows that there is a good correlation between the concentrations of phosphate and nitrogen. The ratio of $N / P$ is calculated to be 12.7 by atoms, which is fairly in good agreement with the average value estimated by the other worker." A plot of silicate vs phosphate is illustrated in Fig. 7. The atomic ratio of Si/P is 19.7 , which is similar to the results obtained by Rrcharos in the layer where biological regeneration of plankton appeared to be occurring. ${ }^{\text {) }}$ Therefore, the following combination can be found from these regression;

$$
\mathbf{P}: \mathrm{N}: \mathrm{Si}=1: 12.7: 19.7
$$

However, the plots characterizing $\mathrm{Si} / \mathrm{P}$ atomic ratio which shows increasing concentrations of phosphate and silicate, show a trend to gather around the upper line set in Fig. 7. Referring to Fig. 2, this implies the Si/P atomic ratio in situ increases gradually with depth. Similar trend has been observed in waters near the Kuroshio and the Oyashio regions. ${ }^{8,9)}$ KAMATANI and UENo certified experimentally that the ratio of $\mathrm{Si} / \mathrm{P}$ increased exponentially as decomposition of phytoplankton assemblages proceeded. ${ }^{\left({ }^{(0)}\right.}$

Seasonal Fluctuations of Pigments

The seasonal fluctuations of the cumulative

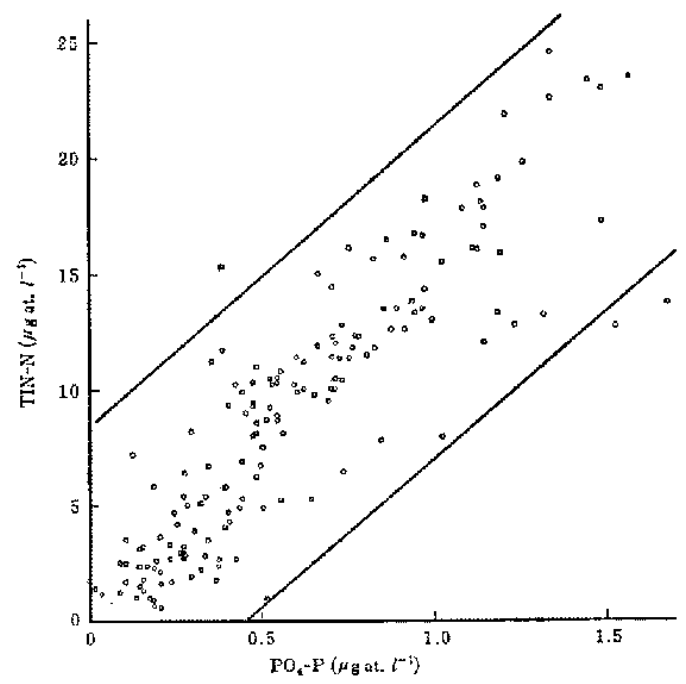

Fig. 6. Relationship between phosphate and total inorganic nitrogen (TIN). Straight lines represent the upper- and lower-limit of $95 \%$ confidence level calculated by the least squares method.

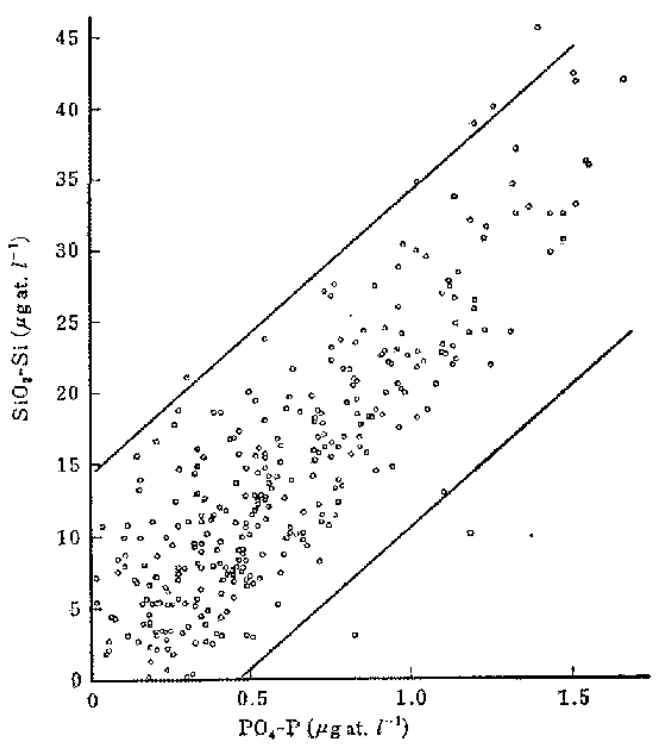

Fig. 7. Relationship between phosphate and silicate. Stright lines represent the upper- and lowerlimit of $95 \%$ confidence level calculated by the least squares method.

amount of chl. $a$ and total pigments (chl. a plus pheo-pigment) from surface to $200 \mathrm{~m}$ depth in a water column, are illustrated in Fig. 8 , in which the chl. a content is not more than $40 \%$ of the total pigments throughout the observation period. The fluctuations are irregular, so it is hardly pos- 


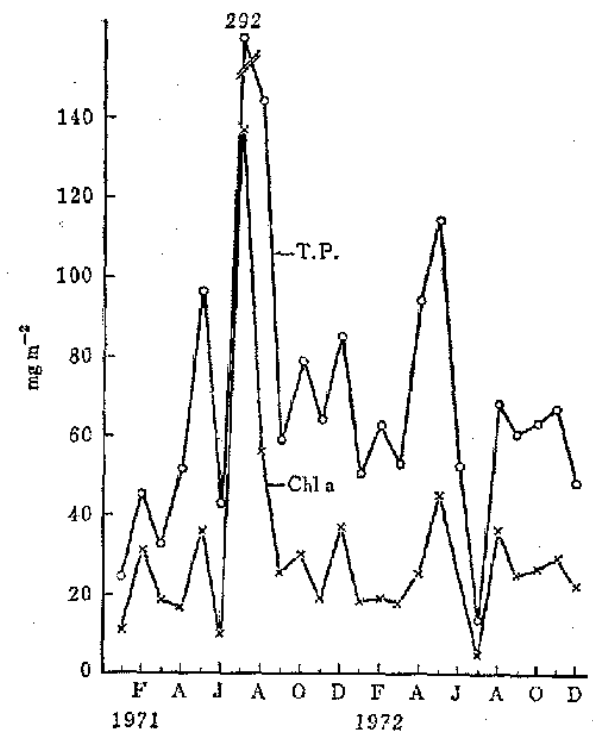

Fig. 8. Seasonal distributions of total pigments (T. P.) and chlorophyll $a$, in $\mathrm{mg}$ per square meter of water column from surface to $200 \mathrm{~m}$.

sible to conclude from this figure that the concentration of chl, $a$ undergoes conventional seasonal cycles appearing the maxima in spring or autumn and the minima in winter and summer; the maximum concentration of chl. $a$ occured in July 1971 at the level of $139 \mathrm{mg} \mathrm{m}^{-2}$ with the fairly high values in August 1971 and May 1972, and the minimum level of $5 \mathrm{mg} \mathrm{m}^{-2}$ in July 1972 . It is also difficult to infer any relationship between the seasonal fluctuations of the pigments and those of nutrients. One reason for this inconsistency could perhaps be attributed to the intensive grazing which is concomitant to an increase in the primary production. It could also be ascribed to a time lag between the supply of nutrients due to mixing and the starting of phytoplankton bloom. At times it may be caused by the swift dispersing an assemblage of the growing phytopiankton, before it could form a large community. In any case, the nutrients supplied by the infusion of cold water would be expected to give some potential capacity to in- itiate phytoplankton blooming.

Conclusively, the present study indicated the fuctuations of temperature and nutrients in long time interval, but these events was considered to change in short time scale. It is desirable in future that more short-time interval observation should be done to get more accurate knowledge about temporal primary production mechanisms in connection with the fluctuations of temperature and nutrients.

\section{Acknowledgements}

The authors are grateful to Professor emeritus K. Hogersu, Tokyo Meteropolitan University and Professor Y. SAiJo, Nagoya University, for their encouragement of this investigation. This research was supported by the Japanese Ministry of Education under the special project research grant (JIP/PM).

\section{References}

1) N. Ogura, A. Kamatani, N. Nakamoto, M. Funakosh, and S. Inata: J. Oceanogr. Soc. Japan, 31, 43-47 (1973).

2) J. D. H. Stratckland and T. R. Parsons: Fish. Res. Bd. Canada Bull, 167, 311 pp. (1968).

3) C. J. LORENZEN: Limnol. Oceanogr., 12, 343-346 (1967).

4) Kaiyo Kansoku Shishin (Manual of Oceanographic Observations), Occanographical Society of Japan, Tokyo, 1970, $427 \mathrm{pp}$.

5) Kaiyo Sokuho (a weekly pub.), Maritime Safety Agency, Tokyo, 1971-1973.

6) A. C. Redfield, B. H. Ketchum, and F.A. Richars: in "The Sea" (ed. by N. N Hill) Vol, 2, Interscience Publ., 1963, pp. 26-77.

7) F. A. RICHARds: J. Mar. Res., 17, 449-465 (1958).

8) Y. SUGrura and H. Yoshimura: J. Oceanogr. Soc. Japan, 20, 14-23 (1963).

9) Y. SugruRA and S. Chatriamovong: J. Oceanogr. Soc. Japan, 20, 89-92 (1964).

10) A. Kamatani and Y. Ueno: Bull. Japan. Soc. Sci. Fish., 45, 537-542 (1980). 